\title{
Zeliha Atioğlu*
}

\section{Crystal structure of (1E)- $N^{\prime}-[(1 E)-1-(4-c h l o r o p h e n y l)$ ethylidene]-2-[1-(4-chlorophenyl)ethylidene] hydrazine-1-carbohydrazonamide, $\mathrm{C}_{17} \mathrm{H}_{17} \mathrm{Cl}_{2} \mathrm{~N}_{5}$}

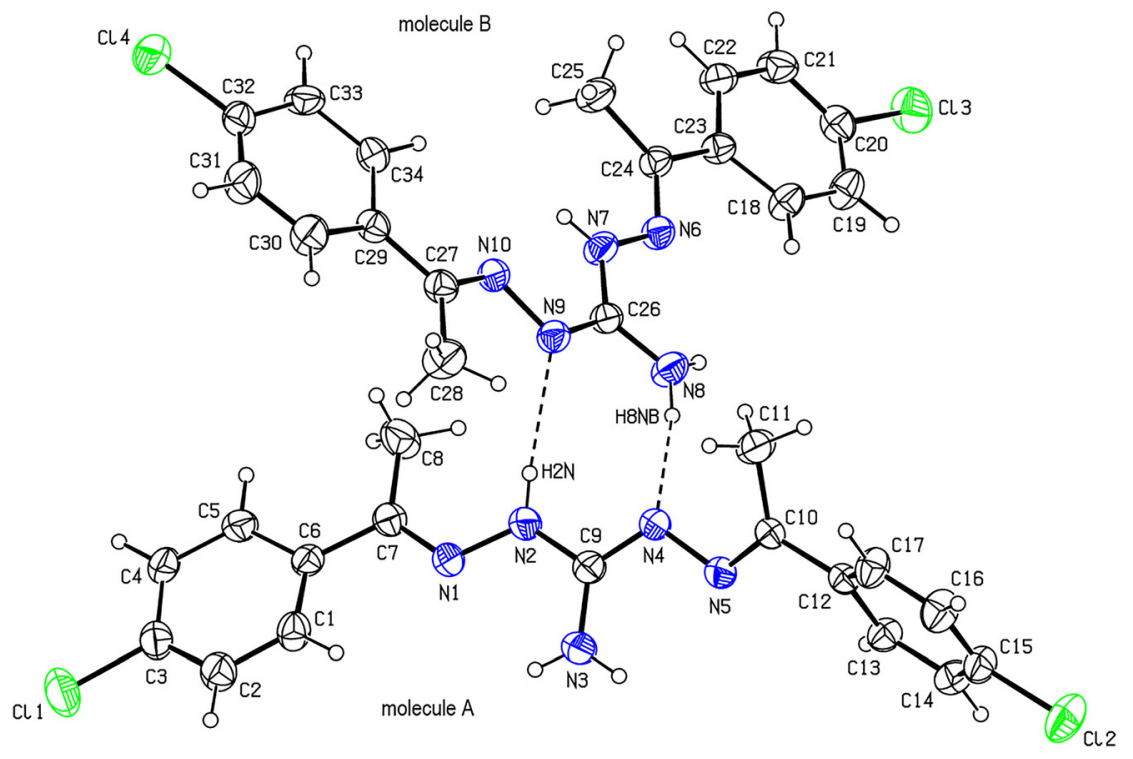

Figure 1: A perspective view of the asymmetric unit of the title compound. Displacement ellipsoids are drawn at the $30 \%$ probability level. The two molecules (A and $B$ ) in the asymmetric unit are linked by $\mathrm{N}-\mathrm{H} \cdots \mathrm{N}$ hydrogen bonds shown as dashed lines. Only the major component of the disordered atoms is shown for clarity. https://doi.org/10.1515/ncrs-2021-0322

Received August 6, 2021; accepted September 10, 2021;

published online September 22, 2021

\section{Abstract}

$\mathrm{C}_{17} \mathrm{H}_{17} \mathrm{Cl}_{2} \mathrm{~N}_{5}$, monoclinic, $P 2_{1} / c$ (no. 14), $a=14.603(2) \AA$, $b=24.059(4) \AA, c=10.1380(16) \AA, \beta=93.141(3)^{\circ}$, $V=3556.4(10) \AA^{3}, Z=8, R_{g t}(\mathrm{~F})=0.0512, w R_{r e f}\left(F^{2}\right)=0.1416$, $\mathrm{T}=296(2) \mathrm{K}$.

\section{CCDC no.: 2108841}

Table 1 contains crystallographic data and Table 2 contains the list of the atoms including atomic coordinates and displacement parameters.

*Corresponding author: Zeliha Atioğlu, Avionics Department, School of Applied Sciences, Cappadocia University, 50420, Mustafapaşa, Ürgüp, Nevşehir, Turkey, E-mail: zeliha.atioglu@kapadokya.edu.tr. https://orcid.org/0000-0002-1141-5151

Table 1: Data collection and handling.

Crystal:

Size:

Wavelength:

$\mu$ :

Diffractometer, scan mode:

$\theta_{\text {max }}$, completeness:

$N(h k l)_{\text {measured }} N(h k l)_{\text {unique }}, R_{\text {int }}$ :

Criterion for $l_{\mathrm{obs}}, N(h k l)_{\mathrm{gt}}$ :

$N(\text { param) })_{\text {refined: }}$

Programs:

\author{
Yellow irregular \\ $0.32 \times 0.22 \times 0.12 \mathrm{~mm}$ \\ Mo $K \alpha$ radiation $(0.71073 \AA)$ \\ $0.37 \mathrm{~mm}^{-1}$ \\ Bruker APEX-II, $\varphi$ and $\omega$ \\ $27.6^{\circ},>99 \%$ \\ $30263,8240,0.049$ \\ $I_{\text {obs }}>2 \sigma\left(I_{\text {obs }}\right), 4576$ \\ 474 \\ Bruker [1], SHELX [2, 3], \\ WinGX/ORTEP [4], PLATON \\ [5]
}

\section{Source of material}

Weigh 2 g (0.0159 mol) 1,3-diaminoguanidine hydrochloride salt and put into a $100 \mathrm{~mL}$ flask. It is dissolved in a mixture of purified water $(15 \mathrm{~mL})$ and methanol $(15 \mathrm{~mL})$, and $4.13 \mathrm{~mL}$ (2.2 eq) of 4-methylbenzaldehyde is added. After mixing at room for $24 \mathrm{~h}$ in a magnetic stirrer, it is 
Table 2: Fractional atomic coordinates and isotropic or equivalent isotropic displacement parameters $\left(\AA^{2}\right)$.

\begin{tabular}{|c|c|c|c|c|}
\hline Atom & $x$ & $y$ & $z$ & $U_{\text {iso }} * / U_{\text {eq }}$ \\
\hline C1 & 0.98245 (18) & $0.17607(12)$ & $0.4007(3)$ & 0.0594 (7) \\
\hline $\mathrm{H} 1$ & 0.936791 & 0.161750 & 0.342835 & 0.071 * \\
\hline $\mathrm{C} 2$ & 1.06576 (19) & $0.14891(13)$ & $0.4150(3)$ & $0.0655(8)$ \\
\hline $\mathrm{H} 2$ & 1.075867 & 0.116554 & 0.367751 & 0.079 * \\
\hline C3 & 1.13303 (18) & 0.17007 (13) & $0.4992(3)$ & $0.0602(7)$ \\
\hline$C 4^{\mathrm{a}}$ & $1.1233(6)$ & 0.2205 & $0.5598(10)$ & 0.0640 (19) \\
\hline $\mathrm{H} 4^{\mathrm{a}}$ & 1.172001 & 0.236487 & 0.609086 & $0.077^{*}$ \\
\hline$C 5^{\mathrm{a}}$ & $1.0390(8)$ & $0.2472(5)$ & $0.5458(12)$ & $0.062(2)$ \\
\hline $\mathrm{H} 5^{\mathrm{a}}$ & 1.031192 & 0.281168 & 0.587349 & $0.074^{\star}$ \\
\hline$C 4 A^{b}$ & 1.1079 (18) & $0.2084(12)$ & $0.587(3)$ & 0.0640 (19) \\
\hline$H 4 A^{b}$ & 1.147163 & 0.216109 & 0.659733 & $0.077^{\star}$ \\
\hline$C 5 A^{b}$ & $1.026(2)$ & $0.2365(14)$ & $0.572(4)$ & $0.062(2)$ \\
\hline $\mathrm{H} 5 \mathrm{~A}^{\mathrm{b}}$ & 1.012441 & 0.264172 & 0.631923 & $0.074^{*}$ \\
\hline C6 & $0.96532(16)$ & $0.22390(10)$ & $0.4702(2)$ & $0.0473(6)$ \\
\hline C7 & $0.87451(17)$ & $0.25136(11)$ & $0.4591(3)$ & $0.0517(6)$ \\
\hline C8 & $0.8611(2)$ & 0.30554 (13) & $0.5271(3)$ & $0.0796(10)$ \\
\hline H8A & 0.888836 & 0.334761 & 0.478693 & $0.119^{*}$ \\
\hline $\mathrm{H} 8 \mathrm{~B}$ & 0.889033 & 0.303935 & 0.614943 & $0.119 *$ \\
\hline $\mathrm{H} 8 \mathrm{C}$ & 0.796630 & 0.312765 & 0.531419 & $0.119^{*}$ \\
\hline C9 & $0.65586(17)$ & $0.21923(11)$ & $0.3180(3)$ & $0.0514(6)$ \\
\hline C10 & $0.45869(15)$ & $0.24199(10)$ & $0.1447(2)$ & $0.0455(6)$ \\
\hline C11 & $0.4755(2)$ & $0.30013(12)$ & $0.1001(3)$ & 0.0724 (9) \\
\hline H11A & 0.528470 & 0.300823 & 0.048014 & 0.109 * \\
\hline H11B & 0.485903 & 0.323731 & 0.175833 & $0.109^{*}$ \\
\hline $\mathrm{H} 11 \mathrm{C}$ & 0.423063 & 0.313192 & 0.047919 & $0.109 *$ \\
\hline C12 & $0.37824(15)$ & $0.21137(10)$ & $0.0876(2)$ & $0.0442(6)$ \\
\hline C13 & 0.33074 (17) & $0.17375(11)$ & $0.1612(3)$ & $0.0512(6)$ \\
\hline H13 & 0.349573 & 0.167554 & 0.249076 & $0.061^{*}$ \\
\hline C14 & 0.25601 (19) & $0.14530(11)$ & $0.1066(3)$ & $0.0594(7)$ \\
\hline H14 & 0.224226 & 0.120529 & 0.157699 & $0.071^{\star}$ \\
\hline C15 & $0.22890(18)$ & $0.15369(12)$ & $-0.0229(3)$ & $0.0592(7)$ \\
\hline C16 & $0.2755(2)$ & $0.18980(13)$ & $-0.0987(3)$ & $0.0684(8)$ \\
\hline H16 & 0.257431 & 0.194755 & -0.187287 & $0.082^{\star}$ \\
\hline C17 & $0.34912(18)$ & 0.21879 (13) & $-0.0436(3)$ & $0.0611(7)$ \\
\hline H17 & 0.379916 & 0.243824 & -0.095220 & $0.073^{\star}$ \\
\hline N1 & 0.81069 (14) & $0.22430(9)$ & $0.3944(2)$ & $0.0522(5)$ \\
\hline N2 & $0.72570(15)$ & $0.24858(10)$ & $0.3799(2)$ & $0.0584(6)$ \\
\hline $\mathrm{H} 2 \mathrm{~N}$ & $0.721(2)$ & $0.2824(12)$ & $0.370(3)$ & $0.070^{*}$ \\
\hline N3 & $0.66766(18)$ & $0.16488(10)$ & $0.3000(3)$ & $0.0710(8)$ \\
\hline H3NA & $0.716(2)$ & 0.1505 (14) & $0.324(3)$ & $0.085^{\star}$ \\
\hline H3NB & $0.624(2)$ & $0.1462(14)$ & $0.265(3)$ & $0.085^{\star}$ \\
\hline N4 & 0.58347 (13) & $0.24812(8)$ & $0.2838(2)$ & $0.0541(5)$ \\
\hline N5 & $0.51198(13)$ & $0.21556(8)$ & $0.2278(2)$ & $0.0496(5)$ \\
\hline $\mathrm{Cl} 1$ & $1.23700(5)$ & $0.13522(4)$ & $0.52022(10)$ & $0.0941(3)$ \\
\hline $\mathrm{Cl} 2$ & $0.13562(6)$ & $0.11783(4)$ & $-0.09404(10)$ & $0.0943(3)$ \\
\hline $\mathrm{C} 18^{\mathrm{a}}$ & $0.4264(7)$ & $0.4648(5)$ & $0.7502(11)$ & 0.0581 (19) \\
\hline $\mathrm{H} 18^{\mathrm{a}}$ & 0.422294 & 0.434609 & 0.693014 & $0.070^{*}$ \\
\hline $\mathrm{C} 19^{\mathrm{a}}$ & $0.3583(7)$ & $0.4732(5)$ & $0.8365(10)$ & 0.0617 (19) \\
\hline $\mathrm{H} 19^{\mathrm{a}}$ & 0.308137 & 0.449396 & 0.836773 & $0.074^{*}$ \\
\hline $\mathrm{C} 18 \mathrm{~A}^{\mathrm{a}}$ & $0.4481(19)$ & $0.4565(15)$ & $0.778(3)$ & 0.0581 (19) \\
\hline $\mathrm{H} 18 \mathrm{~A}^{\mathrm{a}}$ & 0.457363 & 0.421667 & 0.740926 & $0.070^{\star}$ \\
\hline$C 19 A^{a}$ & $0.3810(18)$ & 0.4639 (14) & $0.864(3)$ & 0.0617 (19) \\
\hline$H 19 A^{a}$ & 0.344311 & 0.434008 & 0.885106 & $0.074^{*}$ \\
\hline $\mathrm{C} 20$ & $0.36573(18)$ & $0.51709(12)$ & $0.9218(3)$ & $0.0567(7)$ \\
\hline
\end{tabular}

Table 2: (continued)

\begin{tabular}{|c|c|c|c|c|}
\hline Atom & $x$ & $y$ & $z$ & $U_{\text {iso }}{ }^{*} / U_{\mathrm{eq}}$ \\
\hline C21 & $0.4329(2)$ & $0.55541(12)$ & $0.9122(3)$ & $0.0657(8)$ \\
\hline $\mathrm{H} 21$ & 0.433523 & 0.587146 & 0.964623 & 0.079 * \\
\hline $\mathrm{C} 22$ & 0.50043 (19) & $0.54719(11)$ & $0.8245(3)$ & $0.0611(7)$ \\
\hline H22 & 0.546093 & 0.573863 & 0.818411 & $0.073^{\star}$ \\
\hline $\mathrm{C} 23$ & $0.50231(17)$ & $0.50082(10)$ & $0.7460(2)$ & $0.0476(6)$ \\
\hline $\mathrm{C} 24$ & $0.57422(16)$ & $0.49163(10)$ & $0.6518(2)$ & $0.0468(6)$ \\
\hline $\mathrm{C} 25$ & $0.6417(2)$ & $0.53660(12)$ & $0.6260(3)$ & $0.0659(8)$ \\
\hline $\mathrm{H} 25 \mathrm{~A}$ & 0.698988 & 0.528675 & 0.673364 & 0.099* \\
\hline $\mathrm{H} 25 \mathrm{~B}$ & 0.618511 & 0.571593 & 0.655117 & $0.099^{*}$ \\
\hline $\mathrm{H} 25 \mathrm{C}$ & 0.651020 & 0.538387 & 0.533120 & 0.099 * \\
\hline $\mathrm{C} 26$ & $0.63407(16)$ & $0.38669(10)$ & $0.4322(2)$ & $0.0466(6)$ \\
\hline $\mathrm{C} 27$ & $0.82185(17)$ & 0.40787 (11) & $0.2563(2)$ & $0.0504(6)$ \\
\hline $\mathrm{C} 28$ & $0.8205(2)$ & $0.35922(13)$ & $0.1632(3)$ & 0.0767 (9) \\
\hline $\mathrm{H} 28 \mathrm{~A}$ & 0.760575 & 0.342657 & 0.158847 & $0.115^{\star}$ \\
\hline $\mathrm{H} 28 \mathrm{~B}$ & 0.864980 & 0.332252 & 0.194557 & $0.115^{\star}$ \\
\hline $\mathrm{H} 28 \mathrm{C}$ & 0.834984 & 0.371678 & 0.076882 & $0.115^{\star}$ \\
\hline $\mathrm{C} 29$ & $0.89736(17)$ & $0.44853(10)$ & $0.2558(2)$ & $0.0485(6)$ \\
\hline C30 & $0.9702(2)$ & $0.44238(13)$ & $0.1747(3)$ & $0.0699(8)$ \\
\hline H3O & 0.968988 & 0.413300 & 0.114229 & $0.084^{\star}$ \\
\hline C31 & 1.04427 (19) & $0.47792(13)$ & $0.1810(3)$ & 0.0709 (8) \\
\hline H31 & 1.092401 & 0.472538 & 0.125936 & $0.085^{\star}$ \\
\hline C32 & $1.04652(17)$ & $0.52066(11)$ & $0.2675(3)$ & $0.0552(7)$ \\
\hline $\mathrm{C} 33^{\mathrm{a}}$ & $0.9718(8)$ & $0.5331(4)$ & $0.3408(12)$ & $0.064(2)$ \\
\hline $\mathrm{H} 33^{\mathrm{a}}$ & 0.971449 & 0.564752 & 0.393490 & $0.076^{\star}$ \\
\hline $\mathrm{C} 34^{\mathrm{a}}$ & $0.8958(7)$ & $0.4963(5)$ & $0.3333(11)$ & 0.0593 (19) \\
\hline $\mathrm{H} 34^{\mathrm{a}}$ & 0.844527 & 0.504121 & 0.380481 & $0.071^{*}$ \\
\hline $\mathrm{C} 33 \mathrm{~A}^{\mathrm{b}}$ & $0.983(3)$ & $0.5188(11)$ & $0.361(4)$ & $0.064(2)$ \\
\hline $\mathrm{H} 33 \mathrm{~A}^{\mathrm{b}}$ & 0.989021 & 0.543121 & 0.432118 & $0.076^{*}$ \\
\hline$C 34 A^{b}$ & 0.9169 (18) & $0.4868(13)$ & $0.356(3)$ & 0.0593 (19) \\
\hline $\mathrm{H} 34 \mathrm{~A}^{\mathrm{b}}$ & 0.877315 & 0.488219 & 0.424784 & $0.071^{*}$ \\
\hline N6 & $0.57311(14)$ & $0.44386(9)$ & $0.5944(2)$ & 0.0499 (5) \\
\hline N7 & 0.63867 (15) & $0.43353(9)$ & $0.5060(2)$ & $0.0549(6)$ \\
\hline $\mathrm{H} 7 \mathrm{~N}$ & 0.6796 (19) & 0.4547 (12) & $0.494(3)$ & $0.066^{\star}$ \\
\hline N8 & $0.56333(17)$ & $0.35217(11)$ & $0.4463(3)$ & $0.0610(6)$ \\
\hline H8NA & $0.530(2)$ & $0.3569(12)$ & $0.506(3)$ & 0.073 * \\
\hline H8NB & 0.5619 (19) & $0.3212(13)$ & $0.397(3)$ & $0.073^{*}$ \\
\hline N9 & $0.69490(14)$ & $0.37425(8)$ & $0.3462(2)$ & $0.0501(5)$ \\
\hline N10 & $0.76155(13)$ & $0.41545(8)$ & $0.3417(2)$ & $0.0470(5)$ \\
\hline $\mathrm{Cl} 3$ & $0.28131(5)$ & $0.52635(4)$ & $1.03409(8)$ & 0.0800 (3) \\
\hline $\mathrm{Cl} 4$ & $1.14287(5)$ & $0.56361(3)$ & $0.28543(9)$ & 0.0797 (3) \\
\hline
\end{tabular}

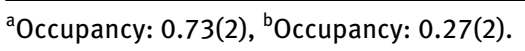

refluxed for $2 \mathrm{~h}$, then the reaction is stopped, cooled to room temperature and neutralized with $0.64 \mathrm{~g}$ (1 eq) $\mathrm{NaOH}$. For precipitation the mixture is kept in the refrigerator for $30-45 \mathrm{~min}$, the precipitated material is filtered with a crucible, washed with distilled water $(3 \times 5 \mathrm{~mL})$ and dried under vacuum. After waiting for one day, crystallization is performed in ethanol (EtOH), kept in the refrigerator for $24 \mathrm{~h}$, the crystalline substance formed is filtered, washed in cold ethanol, the impurity of the substance is checked with TLC (Thin Layer 
Chromatogram) paper, then dried in a vacuum oven. $5.05 \mathrm{~g}$ and the yield was $94 \%$.

\section{Experimental details}

The hydrogen atoms of the $\mathrm{NH}$ and $\mathrm{NH}_{\mathbf{2}}$ groups of molecules $\mathrm{A}$ and $\mathrm{B}$ were located from a difference-Fourier map and refined freely with $U_{i s o}(\mathrm{H})=1.5 U_{e q}(\mathrm{~N})$. All C-bound $\mathrm{H}$ atoms were refined using a riding model with $\mathrm{d}(\mathrm{C}-\mathrm{H})=0.93 \AA, U_{\text {iso }}(\mathrm{H})=1.2 U_{e q}(\mathrm{C})$ for aromatic and $0.96 \AA, U_{i s o}(\mathrm{H})=1.5 U_{e q}(\mathrm{C})$ for methyl $\mathrm{H}$ atoms. Atoms C4, $\mathrm{C} 5, \mathrm{C} 18, \mathrm{C} 19, \mathrm{C} 33$ and $\mathrm{C} 34$ of the chlorobenzene rings of molecules A and B were refined as disordered over two sets of sites with site occupancies of 0.73 (2) and 0.27 (2). Ellipsoid displacement (EADP) constraints were applied to disordered atom groups $\mathrm{C} 4 / \mathrm{C} 4 \mathrm{~A}, \mathrm{C} 5 / \mathrm{C} 5 \mathrm{~A}, \mathrm{C} 18 / \mathrm{C} 18 \mathrm{~A}$, C19/C19A, C33/C33A and C34/C34A.

\section{Comment}

Aminoguanidine is a guanidine derivative known for centuries. It is a compound that is structurally similar to the amino acid L-arginine, which contains a guanidine structure. In addition, aminoguanidine is an important molecule in the formation of nitric oxide by the catalytic effect of nitric oxide synthase [6]. In addition, aminoguanidine was administered to rats with cataracts and it was stated that aminoguanidine had cataract-preventing activity in this application. In recent years, aminoguanidine has been found to be a new promising compound that delays aging. At the same time, it has been observed that atherosclerosis, which increases with age, decreases with the application of aminoguanidine [7].

Moreover, compounds containing an imidazole core are structural isosteres of naturally occurring nucleotides, allowing them to readily interact with biopolymers responsible for numerous biological activities and functions of the living system [8].

There is no symmetry relationship between two molecules A (with Cl1) and B (with $\mathrm{Cl} 3$ ) of the title compound in the asymmetric unit Figure 1. The dihedral angles between the aromatic rings $(\mathrm{C} 1-\mathrm{C} 6, \mathrm{C} 12-\mathrm{C} 17$ and $\mathrm{C} 18-\mathrm{C} 22, \mathrm{C} 29-$ C34) of the major components of the disordered molecules $\mathrm{A}$ and $\mathrm{B}$ are $86.6(2)$ and $6.0(3)^{\circ}$ for molecule $\mathrm{A}$ and $\mathrm{B}$, respectively. The dihedral angles between the aromatic rings $[(\mathrm{C} 1-\mathrm{C} 3, \mathrm{C} 4 \mathrm{~A}, \mathrm{C} 5 \mathrm{~A}, \mathrm{C} 6),(\mathrm{C} 12-\mathrm{C} 17)$ and $(\mathrm{C} 18 \mathrm{~A}, \mathrm{C} 19 \mathrm{~A}$, C20-C22), (C29-C32,C33A,C34A)] of the minor components of the disordered molecules $A$ and $B$ are 88.3(7) and 19.2(9) for molecule $A$ and $B$, respectively. The conformations of the molecules $\mathrm{A}$ and $\mathrm{B}$ are different. This may be attributed to the different steric interactions that occur due to having the different environments in the crystal.

The bond length values in the title compound can be compared with those of the related compounds which are 1,2-bis((pentafluorobenzylidene)amino)guanidine methanol solvate (CSD refcode EMOCIT [9]), 1,3-bis ((pentafluorobenzylidene)amino)guanidinium benzoate benzoic acid solvate (EMOCUF [9]) and 1,3-bis((1-naphthylmethylene) amino)guanidinium benzoate benzoic acid solvate (EMOCOZ [9]).

In the crystal, molecules $\mathrm{A}$ and $\mathrm{B}$ are connected by $\mathrm{N}-$ $\mathrm{H} \cdots \mathrm{N}$ hydrogen bonds [N2-H2N/N9: H2N/N9 $=2.25(3) \AA$, $\mathrm{N} 2 / \mathrm{N} 9=3.073(3) \AA$ with angle at $\mathrm{H} 2 \mathrm{~N}=175(3)^{\circ}$ and N8$\mathrm{H} 8 \mathrm{NB} / \mathrm{N} 4: \mathrm{H} 8 \mathrm{NB} / \mathrm{N} 4=2.13(3) \AA$, N8/N4 = 3.020(3) $\AA$ with angle at $\left.\mathrm{H} 8 \mathrm{NB}=170(3)^{\circ}\right]$, forming a $\mathrm{R}_{2}^{2}(8)$ ring motif parallel to the (001) plane. Furthermore, molecules are linked by $\mathrm{C}-$ $\mathrm{H} \cdots \mathrm{Cl}$ contacts $\mathrm{C} 11-\mathrm{H} 11 \mathrm{C} / \mathrm{Cl}^{\mathrm{i}}: \mathrm{H} 11 \mathrm{C} / \mathrm{Cl}^{\mathrm{i}}=2.99 \AA$, $\mathrm{C} 11 /$ $\mathrm{Cl}^{\mathrm{i}}=3.860(3) \AA$ with angle at $\mathrm{H} 11 \mathrm{C}=151.9^{\circ}$ for symmetry operation (i): $-1+x, 1 / 2-y,-1 / 2+z$; $\mathrm{C} 19-\mathrm{H}_{19} / \mathrm{Cl}^{\mathrm{ii}}{ }^{\mathrm{ii}} \mathrm{H} 19 /$ $\mathrm{Cl}^{\mathrm{ii}}=2.98 \AA, \mathrm{C} 19 / \mathrm{Cl}^{\mathrm{ii}}=3.711(10) \AA$ with angle at $\mathrm{H} 19=136.3^{\circ}$ for (ii): $-1+x, 1 / 2-y, 1 / 2+z$; $\mathrm{C} 19 \mathrm{~A}-\mathrm{H} 19 \mathrm{~A} / \mathrm{Cl}^{\mathrm{ii}}: \mathrm{H} 19 \mathrm{~A} /$ $\mathrm{Cl}^{\mathrm{ii}}=2.71 \AA, \mathrm{C} 19 \mathrm{~A} / \mathrm{Cl}^{\mathrm{ii}}=3.60(3) \AA$ with angle at $\mathrm{H} 19 \mathrm{~A}=161.8^{\circ}$ for (ii): $-1+x, 1 / 2-y, 1 / 2+z$ and C33-H33/ $\mathrm{Cl} 2^{\text {iii. }}: \mathrm{H} 33 / \mathrm{Cl}^{2} 2^{\text {iii }}=2.93 \AA, \mathrm{C} 33 / \mathrm{Cl}^{\text {iii }}=3.694(11) \AA$ with angle at $\mathrm{H} 33=140.9^{\circ}$ for (iii): $\left.1-x, 1 / 2+y, 1 / 2-z\right], \mathrm{C}-\mathrm{Cl} \cdots \pi$ interactions $\quad\left[\mathrm{C} 15-\mathrm{Cl} 2 / \mathrm{Cg}(\mathrm{C} 29-\mathrm{C} 34)^{\mathrm{iv}}: \quad \mathrm{Cl} 2 / \mathrm{Cg}(\mathrm{C} 29-\right.$ $\mathrm{C} 34)^{\mathrm{iv}}=3.729(3) \AA$ 跑 angle at $\mathrm{Cl} 2=167.09(11)^{\circ}$; $\mathrm{C} 15-\mathrm{Cl} 2 /$ $\mathrm{Cg}(\mathrm{C} 29-\mathrm{C} 32 / \mathrm{C} 33 \mathrm{~A}, \mathrm{C} 34 \mathrm{~A})^{\mathrm{iv}}: \quad \mathrm{Cl} 2 / \mathrm{Cg}(\mathrm{C} 29-\mathrm{C} 32 / \mathrm{C} 33 \mathrm{~A}, \mathrm{C} 34 \mathrm{~A})^{\mathrm{iv}}$ $=3.590(8) \AA$ with angle at $\mathrm{Cl} 2=167.21(16)^{\circ}$ for (iv) $-1+x$, $1 / 2-y,-1 / 2+z]$ and $\pi-\pi$ stacking interactions [Cg1 $(\mathrm{C} 18-\mathrm{C} 23) \cdots \mathrm{Cg} 1(\mathrm{C} 18-\mathrm{C} 23)^{\mathrm{v}}=3.892(4) \AA$, angle $=0.0(3)^{\circ}$ and slippage $=1.68 \AA$; $\mathrm{Cg} 2(\mathrm{C} 20-\mathrm{C} 23 / \mathrm{C} 18 \mathrm{~A}, \mathrm{C} 19 \mathrm{~A}) \cdots \mathrm{Cg} 2$ $(\mathrm{C} 20-\mathrm{C} 23 / \mathrm{C} 18 \mathrm{~A}, \mathrm{C} 19 \mathrm{~A})^{\mathrm{v}}=3.618(10) \AA$, angle $=0.0(9)^{\circ}$ and slippage $=1.15 \AA$ for (v) $1-x, 1-y, 2-\mathrm{z}$, forming a threedimensional network.

Author contributions: The author has accepted responsibility for the entire content of this submitted manuscript and approved submission.

Research funding: None declared.

Conflict of interest statement: The author declares no conflicts of interest regarding this article.

\section{References}

1. Bruker. APEX2 and SAINT. Bruker AXS Inc.: Madison, WI, USA, 2012.

2. Sheldrick G. M. A short history of SHELX. Acta Crystallogr. 2008, A64, 112-122.

3. Sheldrick G. M. Crystal structure refinement with SHELXL. Acta Crystallogr.. 2015, C71, 3-8. 
4. Farrugia L. J. WinGX and ORTEP for Windows: an update. J. Appl. Crystallogr. 2012, 45, 849-854.

5. Spek A. L. Structure validation in chemical crystallography. Acta Crystallogr 2009, D65, 148-155.

6. Parlakpınar H., Örüm M., Acet A. Aminoguanidine and cardiovascular system. Ann. Health Sci. Res. 2012, 2, 9-14.

7. Özgüneş H., Atasayar S. Aminoguanidine and the its significance in diseases: review. Türkiye Klinikleri J. Med. Sci., 29, 976-986.
8. Çağlar Yavuz S. Synthesis and in Vitro Cytotoxic Activity Studies of Compounds Containing Pyrimidine and Imidazole Nucleus. PhD Thesis, Erciyes University, Graduate School of Natural and Applied Sciences, Department of Chemistry, 2019; pp. 1-275.

9. Bose P., Ahamed B. N., Ghosh P. Functionalized guanidinium chloride based colourimetric sensors for fluoride and acetate: single crystal X-ray structural evidence of $-\mathrm{NH}$ deprotonation and complexation. Org. Biomol. Chem. 2011, 9, 1972-1979. 